\title{
Brasil e Portugal: antagonismo na construção da narrativa nacional durante a Primeira República
}

\author{
Carolina de Moraes Souza* \\ Francilaine Munhoz Moraes**
}

\section{Resumo \\ O objetivo deste artigo é refletir sobre a separação identitária entre Brasil e Portugal, e suas implicações para a memória coletiva, no processo de construção da narrativa nacional durante a Primeira República (1889-1930). O viés deste trabalho situa o fenômeno no espaço de confluência entre o jornalismo e a história brasileira. O recorte analítico abarca doze edições da revista "Brazilea" no ano de 1917, estudadas com base na concepção narrativa de Ricoeur (1994) e nos construtos acerca da memória (Halbwachs, 1990; Pollak, 1992; Catroga, 2016). Como resultado, a pesquisa revelou: animosidade em relação aos imigrantes portugueses; desprezo pelo legado português, considerado "vicioso", e uma tentativa de banir da narrativa nacional os históricos vínculos entre os países. O estudo percebeu marcas de antagonismo e intolerância, que sugerem vestígios xenófobos contra os portugueses, uma espécie de lusofobia. \\ Palavras-chave: Narrativa. Imigrantes portugueses. Intolerância. Lusofobia. \\ Brazil and Portugal: antagonism in the construction of national narrative during the First Republic}

\footnotetext{
* É doutoranda em História Contemporânea na Universidade de Coimbra (Faculdade de Letras - FLUC), Portugal. Tem mestrado em Comunicação em Jornalismo pela Universidade de Coimbra (Faculdade de Letras - FLUC), Portugal. É bacharel em Jornalismo e Comunicação pelo Centro Universitário - Instituto de Ensino Superior de Brasília (IESB) e em História pela Universidade de Brasília (UnB).

** É mestre e doutora em Comunicação e Sociedade pelo Programa de pós-graduação em Comunicação da Faculdade de Comunicação da Universidade de Brasília (PPGCOM FAC/UnB). É licenciada em Letras pela Universidade de Brasília (LIP/UnB) e em Jornalismo pelo UniCeub.
} 


\section{Abstract}

The purpose of this article is to reflect on the identity separation between Brazil and Portugal, and its implications for collective memory, in the process of building the national narrative during the First Republic (1889-1930). The bias of this work places the phenomenon in the space of confluence between journalism and Brazilian history. The analytical cut comprises twelve editions of the magazine "Brazilea" in 1917, studied based on the narrative conception of Ricoeur (1994) and the constructs about memory (Halbwachs, 1990; Pollak, 1992; Catroga, 2016). As a result, the survey revealed: animosity towards Portuguese immigrants; contempt for the Portuguese legacy, considered "vicious", and an attempt to banish the national ties between countries from the national narrative. The study found signs of antagonism and intolerance, which suggest xenophobic traces against the Portuguese, a kind of lusophobia.

Keywords: Narrative. Portuguese immigrants. Intolerance. Lusophobia.

\section{Introdução}

A Independência brasileira gerou, a partir de 1822, visões contraditórias sobre as relações entre Portugal e Brasil, e embates entre brasileiros e portugueses, que a partir daquele momento tornaram-se imigrantes em solo brasileiro. As relações, até então filiais e fraternais, e a percepção de 'laços de sangue' sofreram mudanças. A concessão de privilégios legais oferecidos aos portugueses alimentou a hostilidade (JANCSÓ E PIMENTA, 1999; RIBEIRO, 2002). Esse antagonismo entre brasileiros e portugueses deixou marcas na memória coletiva e contribuiu para uma narrativa de separação identitária.

O período, que teve início na Independência e perpetuou-se na Primeira República (1889-1930), palco da construção da narrativa nacional, comportava diversas perspectivas, dentre as quais elegemos, nesta pesquisa, a que se consubstancia a partir dos textos publicados na revista "Brazilea", no ano de 1917, cujo teor autoproclamado se propunha à difusão e à defesa do brasileirismo, linha de pensamento que valorizava o nacionalismo nativista.

Dessa forma, este artigo tem como objetivo aclarar a problemática do antagonismo entre brasileiros e portugueses nas narrativas nacionais. A investigação explora elementos que revelam aspectos sociais, culturais e econômicos da realidade naquele período. Pensar a construção da narrativa nacional, no seu nascedouro histórico, e seus vínculos com a memória coletiva, é a contribuição desta pesquisa, que se ampara nos construtos teóricos 
acerca da memória (Halbawachs, 1990; Pollak, 1992; Catroga, 2016) e na concepção narrativa de Ricoeur (1994).

Este trabalho está alinhado à proposta conceitual de Calhoun (1997, p. 170). Nessa perspectiva, as narrativas de identidade nacional ${ }^{\dagger}$ são um fenômeno discursivo que informa e integra os diversos aspectos da nação, ao mediar e garantir a solidariedade interna entre seus integrantes e o reconhecimento externo. Por conseguinte, esta pesquisa reconhece que, pelo cunho jornalístico e histórico, o exercício dessa observação não pode ser meramente descritivo, mas também analítico e reflexivo.

\section{Memória e Narrativa}

Os alicerces desta pesquisa se valem das concepções de memória e narrativa a fim de compreender o fenômeno em estudo e suas imbricações.

A memória, enquanto fenômeno social, pode ser apreendida em contexto de coletividade, cuja principal função é incentivar as relações e os laços entre membros de um grupo social, por meio de seu passado e experiência comuns (HALBWACHS, 1990). Por se tratar, por vezes, de uma herança, a memória pode sofrer alterações que são dependentes do momento em que está sendo articulada e expressa. As intenções do momento podem estruturar um tipo de memória e, dessa forma, pode-se assumir que há uma relação fenomenológica entre memória e narrativa nacional. Essa relação "revela sentimento de continuidade e de coerência de uma pessoa ou de um grupo em sua reconstrução de si" (POLLAK, 1992, p. 5). Em conformidade com Catroga (2016, p. 18), este trabalho considera relevante conceituar a memória segundo a visão que evita tanto o atomismo social quanto o organicismo totalizante. Uma espécie de terceira via que leva em consideração a dimensão coletiva e social da memória, sem excluir a existência da interação entre memória privada e pública. Para o autor, portanto, a memória coletiva surge substantivada como memória histórica e, principalmente, como memória nacional.

\footnotetext{
† Observa-se, neste trabalho, a diferenciação entre os termos nação, identidade nacional e nacionalismo. Conforme propõe Adamec (2014, p. 18), nação corresponde a um grupo social que encarna os ideais políticos e as identidades de seus integrantes, ou seja, ela é um fenômeno que integra as bases identitárias e as perspectivas ideológicas. A identidade nacional é uma identidade coletiva específica, com consciência de pertencimento à nação, e é abrangente, pois ultrapassa divisões de classe, gênero, status e outros. Já o nacionalismo é a defesa ativa (mais ou menos intensa) dos elementos identitários da nação, traduzidos em uma ideologia que deve garantir e propagar os interesses de seus membros interna e externamente.
} 
Entende-se que essa memória nacional pode ser estudada por meio da narrativa. Como coloca Casalegno (2006), dividir uma memória é compartilhá-la em conjunto e é por meio da narrativa que conseguimos restituir as experiências. Dessa forma, a narrativa assume caráter fundador, pois além de ser suplente da experiência compartilhada, ela é também participante da fundação da memória coletiva. Uma memória comum se forma a partir das informações enviadas por membros de um grupo social que nutrem um sistema único, por meio da narrativa.

Nessa linha, este artigo adota a concepção narrativa de Paul Ricoeur (1994), tanto nas noções acerca do termo quanto na compreensão do material em análise. Com base nas ideias de Santo Agostinho (1973) $)^{\ddagger}$ e Aristóteles (2008)§, Ricoeur discute o ato narrativo na obra Tempo e Narrativa (1994). A função mimética da narrativa (mimesis aristotélica) pode ser abarcada como o processo dinâmico de produzir a representação ou a imitação da ação por meio da linguagem. Sendo imitações ou representações do real - e não o real em si -, para ser fiel ao que é imitado, é necessário filtrar, condensar e recriar a realidade, sendo estas as funções da intriga. Nesse entendimento, a tessitura da intriga é um trabalho de composição inteligível da ação e de organização dos acontecimentos. Assim, a intriga pode ser considerada a peça mediadora entre o acontecimento e a história, com objetivo de constituir sentido, de causar inteligibilidade.

Conforme o autor, para decifrar as questões que envolvem a relação entre o tempo e a narrativa, é preciso estabelecer a função mediadora da tessitura da intriga em um processo de mimese. Para tanto, ele sugere estudar a narrativa como o seguimento de um tempo prefigurado (mimese I) em um tempo refigurado (mimese III), passando pela mediação do tempo configurado (mimese II), dinâmica nomeada de tríplice mimese. ${ }^{* *}$

Ainda segundo a perspectiva de Ricoeur, os acontecimentos podem ser modificados, preservados ou ressignificados no momento em que se submetem interpretativamente às estratégias narrativas. Nesse sentido, os acontecimentos possuem dimensões hermenêuticas da consciência histórica, as quais comportam remissões do

\footnotetext{
¥ A obra filosófica "Confissões" foi escrita, provavelmente, entre os anos de 397 e 398.

$\S$ Estima-se que o original de "A Poética" tenha sido escrito no século IV a.c, durante o período de fundação da Escola de Atenas.

** A mimese I (pré-figuração) trata da pré-compreensão do mundo e da ação, a mimese II (configuração) representa o processo de configuração textual e a mimese III (refiguração) se refere às relações entre as mimeses no processo de leitura.
} 


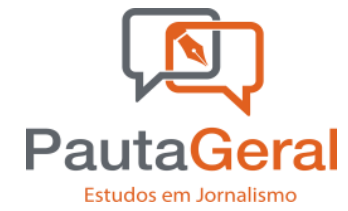

passado e da memória, que geram projeções para o futuro a partir de rastros, indícios, vestígios, símbolos, arquivos e documentos.

À luz desses pressupostos, a intenção deste trabalho é refletir sobre a construção da narrativa nacional, com foco nos aspectos de rompimentos identitários entre Brasil e Portugal, e suas implicações para memória coletiva.

\section{Construção da narrativa nacional}

No século XIX, como afirma Khaled (2010, p. 54), o conceito de nação, como narrativa em construção, se tornou, por excelência, a missão da história como ciência. O passado e a memória marcam a narrativa nacional, como recurso de configuração da cultura e da coesão interna para a construção das nações.

A construção da narrativa nacional brasileira, que permeou os anos seguintes à Independência, foi erigida por intelectuais, artistas, historiadores e sociólogos. Conforme explica o autor, as narrativas nacionais eram expostas nos meios de circulação de conhecimento da época - obras literárias e espaços de encontro, como os gabinetes de leituras - e divulgadas pela imprensa, abrigando visões plurais. Com a proclamação da Independência, parte da intelectualidade brasileira considerava o Brasil uma nação separada de Portugal e outra parte vinculava, por sua vez, "suas lealdades à nação portuguesa". O autor infere: "Percebe-se claramente que a questão identitária - longe de estar assentada - era multifacetada, marcada por vários horizontes identitários" (KHALED, 2010, p. 39).

Nesse universo, a perspectiva nacionalista (ou nativista) sustentava a necessidade de o Brasil se afirmar como uma nação autônoma de Portugal. Essa visão conformou posições, argumentos e sentimentos de animosidade em relação aos portugueses. Tal opinião pública nascente cristalizou-se em uma espécie de "(in) comunicação e estranhamento" entre Brasil e Portugal (FINO, 2019, p. 255). Portanto, os anos que antecederam a proclamação da República no Brasil constituíram narrativas nativistas diferentes daquelas chanceladas pelo 

Mato Grosso§§, a Revolução Praieira e a Revolta da Armada revelaram o uso desses conflitos na política, presente no "Manifesto Republicano" (1870) ${ }^{\star \star *}$, que propalava: "Somos da América, queremos ser americanos" (p. 744).

Com a proclamação da República, em 1889, a oposição aos portugueses se agravou com a imigração em massa. Aos portos, os portugueses desembarcavam em busca de emprego e também de espaço na burguesia comercial. Em 1890, um quinto da população do Rio de Janeiro era de lusitanos e, no período entre 1906 a 1920, entraram no porto do Rio de Janeiro mais de um milhão e cem mil passageiros, na maioria, portugueses. Observou-se, portanto, uma diferença de $73 \%$ no excedente das entradas sobre as saídas entre as datas de 1906 e 1920. Em 1920, a cada dez mil homens estrangeiros na cidade, mais de sete mil eram portugueses ${ }^{\dagger t t}$.

Segundo Ribeiro (2017), o português, naquele momento, passou à concorrente do brasileiro, pois o mercado com poucas oportunidades - a oferta de força de trabalho, com

†† O artigo "Como se deve escrever a história do Brasil" (1844), de Von Martius, e a obra "História geral do Brasil" (1854-1857), de Varnhagen, representavam as necessidades do Estado Brasileiro, que se comprometera a garantir a manutenção do território, a unidade entre regiões heterogêneas, o status quo e a afirmação do regime monárquico no país. Para tanto, essas obras reforçavam o traço comum da colonização portuguesa nas mais diferentes regiões brasileiras - promovendo a coesão e afirmando sua unidade -, valorizavam a atuação dos portugueses no país - mantendo a ligação e o vínculo da história brasileira com a da Europa - e neutralizavam a ação dos liberais e jacobinos (KHALED, 2010, p. 47-51).

ł A noite das garrafadas foi um conflito ocorrido em 13 de março de 1831 no momento em que os portugueses preparavam uma festa para recepcionar $D$. Pedro I no seu retorno ao Rio de Janeiro de uma viagem a Minas Gerais. Os brasileiros, revoltados com o assassinato do jornalista Líbero Badaró - um dos maiores críticos do império - , iniciaram um ataque contra os lusos com garrafas e pedras. Tal episódio ficou conhecido como uma das primeiras manifestações da crise política que resultaria na abdicação do imperador em 7 de abril daquele ano (RIBEIRO, 2002).

$\S \S$ Segundo Lima (2016), o fato ocorreu no período regencial na província de Mato Grosso, e revelou a crescente rivalidade entre portugueses (chamados de bicudos e pés-dechumbo) e brasileiros, causada pelas tensões no mercado de trabalho e no comércio mato-grossense. O conflito surgiu após um boato de que os brasileiros seriam assassinados pelos portugueses e gerou motins com saques e depredações em estabelecimentos de portugueses.

*** BRASILIENSE, Américo. Manifesto Republicano. São Paulo: EADUSP, 1870. Disponível em $<$ https://edisciplinas.usp.br/pluginfile.php/4360902/mod_resource/content/2/manifesto\%20 republicano\%201870.pdf>. Acesso em junho de 2020.

tt† Recenseamento de 1920 da população do Rio de Janeiro (Districto Federal), p. 37 e 58. Disponível em: <https://biblioteca.ibge.gov.br/visualizacao/livros/liv6383.pdf>. Acesso em junho de 2020. 
o fim da escravidão em 1888, era superior às colocações existentes - dava preferência ao trabalhador imigrante e branco devido à disseminação da ideologia de desenvolvimento civilizacional do século XIX, sustentada no processo de embranquecimento da população. Ademais, ainda conforme a autora, patrões e comerciantes portugueses eram acusados de práticas extorsivas nos preços e de exigirem árduas rotinas de trabalho. A noção de exploração econômica, nos setores imobiliários e no comércio a varejo, resultou da concorrência entre a pequena burguesia nacional e a burguesia portuguesa. Para o burguês brasileiro, era oportuno considerar os portugueses como os únicos responsáveis pela crise comercial e habitacional - que resultou na carestia de alimentos e imóveis - a fim de eliminar a concorrência, bem como evitar a ira da população, que por muitas vezes invadiu e saqueou estabelecimentos comerciais.

O ressentimento dos brasileiros em relação aos portugueses também decorreu de alguns privilégios na legislação brasileira concedidos aos imigrantes após a proclamação da República. O Decreto de Naturalização dos Estrangeiros de 1889, conhecido como Grande Naturalização, outorgou a cidadania a estrangeiros residentes no país com o objetivo de estimular a permanência de trabalhadores "no mesmo nível moral, ao lado e a par dos nacionais, a bem do progresso e grandeza do Brasil" (TAUNAY, 1884 apud MENDES, 2010, p. 151). Por esses fatores, a numerosa presença da comunidade lusa imigrada gerou uma onda de patriotismo nativista que se irradiou a partir de um novo eixo de poder. Esse grupo contrapunha a ideia de povo brasileiro à noção de pátria estrangeira, na qual se encaixava o perfil do imigrante português (MENDES, 2011, p. 358).

A oposição atingiu seu ponto máximo em 1894 devido ao rompimento de relações diplomáticas com Portugal, decretado pelo então presidente Floriano Peixoto. O corte nas relações ocorreu porque navios de guerra portugueses, atracados no Rio de Janeiro, concederam asilo aos marinheiros de esquadra que se revoltaram meses antes contra o governo. Tal situação contribuiu para o clima de acirramento, já fomentado pelos jacobinos $\$ \ddagger \ddagger$ - conhecidos como florianistas ou 'radicais da república' (QUEIROZ, 1986; GOMES, 2008) - e alterou a lógica da política externa brasileira.

łł‡ Para Gomes (2008) e Queiroz (1986), no período republicano, os embates políticos entre brasileiros e portugueses se fortaleceram e ganharam espaço com o movimento jacobino, preocupado com a consolidação do novo regime e a rejeição à Monarquia e ao Império, associando-os ao atraso, à exploração e à dominação dos portugueses. 
Nesse ambiente, dois posicionamentos contraditórios se firmaram. De um lado, a presença da intelectualidade portuguesa nas cidades do Rio de Janeiro e de São Paulo era representada por movimentos como a Confederação Luso-Brasileira, que reforçavam o luso-brasileirismo§§§, pelos Gabinetes Reais de Leitura ${ }^{\star * * *}$ e pela imprensa lusitana, ou brasileira dirigida por portugueses ${ }^{\dagger+t \dagger}$.

Em lado oposto, as campanhas nativistas e nacionalistas, como a Propaganda Nativista (1919) e a Ação Social Nacionalista (1920) a autonomia cultural e intelectual brasileira em relação a Portugal e exploravam as diferenças entre as nações em prol do fortalecimento da narrativa nacionalista.

É nesse contexto político, social, econômico e jurisdicional que as expressões de antagonismo se fortaleceram nos jornais, nas revistas, na literatura e na música. Jornais como "O Jacobino", "A Bomba", "O Nacional”, bem como as revistas "Brazilea", "Gil-Blás" e "Revista do Brasil" demonstravam a combatividade nacionalista de seus editores e escritores, que propunham modelos e soluções diferenciados para a nação (RIBEIRO, 2017, p. 134; JESUS, 2012, p. 13). Dentre essas publicações, este trabalho debruça-se sobre a revista "Brazilea".

\section{A revista "Brazilea": imprensa nacionalista}

Segundo De Luca (2011), a revista "Brazilea", fundada em 1917, teve como diretores Arnaldo Damasceno Vieira, Alvaro Bomilcar e Jackson de Figueiredo, pensadores conhecidos por discutir o nacionalismo católico, propor a nacionalização do comércio e

$\S \S \S$ Segundo Alves (2009, p. 13), o luso-brasileirismo defende, em sua fundamentação, uma visão lusófila da história, memória e cultura brasileiras. Pela mediação de agentes e instituições brasileiras e portuguesas, os intelectuais criaram redes de sociabilidade nas duas margens do Atlântico.

${ }^{* * * *}$ Os Gabinetes ressaltavam o vínculo entre as nações, propagando a ideia de paternidade, a qual fortalecia aquilo que era comum a brasileiros e portugueses: a história da colonização (SANTOS, 2018, p. 78).

$\dagger^{\dagger \dagger}+$ Como exemplos de periódicos da colônia luso-carioca publicados no Rio de Janeiro no século XX, citamos: as revistas Portugal llustrado, Portugal e o Almanaque Português; os jornais Diário Portuguêz, Lusitano e Jornal Português. Na década de 20, destaca-se o jornal Pátria Portugueza e a revista Lusitania. Dentre os periódicos brasileiros com vínculo luso, destaca-se o jornal O Paiz, fundado por brasileiros, mas dirigido pelo empresário português João de Sousa Laje nos primeiros anos do século XX (OLIVEIRA, 2004, p. 144).

$\ddagger \ddagger \ddagger \ddagger$ Segundo Oliveira (1990, p. 150), o objetivo da Propaganda Nativista era "despertar a solidariedade entre as nações americanas, defender o mercado de trabalho para os brasileiros e regulamentar a imigração", bem como a preocupação de livrar o Brasil do "parasitismo português", nacionalizando o comércio e a imprensa. 

entre elas a "Variedades" - reflexões sobre a situação política, ideológica e econômica do país - e a "Bibliografia", que sugeria livros, autores e textos alinhados à sua perspectiva editorial. Suas páginas apresentavam poucas imagens e anúncios, muita opinião e crítica, além de alguns poemas e sonetos. A revista adotava uma linguagem rebuscada e, por vezes, sarcástica, como era comum à época.

O nome da revista, com pronúncia correspondente a Brasília, "vem da defesa dos adeptos do nacionalismo nativista em se grafar Brasil e seus derivados com " $Z$ ", para se diferenciar da língua falada em Portugal” (DE LUCA, 2011, p. 67). O programa da revista estabelecia como objetivo a difusão e a defesa do brasileirismo, linha de pensamento que valorizava o nacionalismo nativista e associava os problemas da nação à colonização, à imigração e ao intenso relacionamento com a comunidade portuguesa. "Brazilea" representava, como linha editorial, a visão de seu diretor-fundador, Álvaro Bomílcar.

O mensário propunha diferenciar-se de outros diários e magazines, os quais, segundo a revista, exploravam as coisas europeias ao invés de se ocupar com as searas indígenas, as belezas do país e os progressos morais e econômicos dos brasileiros. A "Brazilea" desejava "desfraldar o pendão do brazileirismo puro e intelectual", representando "os traços differenciaes - ethnographicos e mesológicos - que já se fazem notar até mesmo nos factos da formosa língua que nos herdaram esses rudes antepassados" (BRAZILEA, n. 1, 1917, p. 4).

\section{Análise}

O corpus desta pesquisa engloba doze edições do mensário "Brazilea: sociologia, arte e crítica", do primeiro ano de publicação, 1917£§§§. Para a análise, foram selecionados os textos que tratam sobre Portugal e os portugueses, de forma direta ou por citação. Dessa prospecção, resultaram dezenove textos que referenciam os lusos, suas características, atuações e costumes. Nesse material, prevalecem três matrizes temáticas que apresentam

§§§ É importante ressaltar que a publicação da revista "Brazilea", a partir do número 2 e até o número 12 do ano de 1917, apresenta-se de forma contínua. Ou seja, as edições 2 a 12 da revista estão em uma mesma disposição, num total de 554 páginas. O motivo da publicação estar disposto dessa maneira é desconhecido. Dessa forma, as referências estão marcadas com o n. 2-12 e a página correspondente àquela disponível no site da hemeroteca digital da biblioteca nacional (de 1 a 554). Disponível em: < http://memoria.bn.br/docreader/DocReader.aspx?bib=217425\&PagFis=1>. Acesso em junho de 2020. 
estratégias narrativas (Legado, Intelectualidade, Comércio), exploradas analiticamente a seguir.

\section{a) Legado}

Percebe-se que os editores, jornalistas e colaboradores da revista desaprovavam as ações políticas da Corte Portuguesa. Nos textos publicados em "Brazilea", eles destacam heranças viciosas deixadas pelos portugueses no período colonial e imperial, a exemplo de determinadas características e costumes daquele povo. Também nota-se uma crítica à narrativa oponente, que exaltava a atuação portuguesa na história.

Na primeira edição da revista, o editor Álvaro Bomílcar considera que a colonização portuguesa estimulou a "obra da injustiça e da extorsão", ao "dividir a população em duas grandes classes: senhores e escravos. Aquelles eram os portuguezes, ou seus descendentes; os outros, - os negros e os índios!” (n. 1, p. 25). Para o editor, os mestiços entre as raças, quando eram livres, eram tratados "com rigor; porque se tinha certeza de encontrar sua origem na senzala..." (n.1, p. 25). Decorrem dessa divisão social, segundo Bomílcar, os males da realidade brasileira, considerada uma "terra de magnatas, mas sem povo no alto sentido da palavra" (n. 1, p. 25). Tais males, segundo ele, sustentavam-se pela histórica subalternidade política local em relação a Portugal.

No mesmo texto, Bomílcar reflete sobre a questão da nacionalidade brasileira e ressalta que a política no país não é capaz de educar porque ela não surgiu no "seio da nacionalidade". Em crítica aos legados deixados pelos portugueses, ele conclui que a identidade nacional brasileira é como um "piano velho que nos mandassem de além-mar, com as téclas e cordas bem estragadas" (n.1, p. 28).

$\mathrm{Na}$ quarta edição da revista, Bomílcar argumenta que, apesar de não ser o regime ideal, a República é melhor opção que a Monarquia portuguesa porque esta nunca teve "raízes na massa popular" (n.2-12, p. 151) e se apresenta aos brasileiros como "vício de origem". $\mathrm{Em}$ tom de reprovação, entende que a necessidade de proclamar o passado como um período de glórias, "fundado no bamburrio das navegações" (n.2-12, p. 154), nada mais é que uma retórica discutível, a qual, ao invés de "construir no presente alguma coisa útil e proveitosa, pelo trabalho e cohesão das classes" (p. 153 e 154), prefere lembrar com saudosismos um "péssimo" (p. 152) passado.

Nas edições 6 e 7, os textos apresentam referências a valores e costumes deixados pelos portugueses durante a colonização. A “jactância, trapaça, chicana, prosápia fofa, 
tolice, preguiça e falta de sentimento de dever" (n. 2-12, p. 331) seriam legados de D. João VI. Do mesmo modo, "o preconceito de raça, o racismo, a escravidão, moralidade do latrocínio, barbarismo e o egoísmo" (n. 2-12, p. 281, 360, 370) seriam vícios deixados pelos portugueses.

No texto "O luso-brasileiro", publicado na seção "Variedades" (ed. 7), os colaboradores, em tom irônico, salientam que o "grande amor que nos liga a Portugal e a portuguezes desde o tempo em que os seus patrícios encetaram a obra da civilisação neste país", devese à nossa relação histórica que realizou "processos admiráveis" como "a apologia do incêndio, do latrocínio e do parasitismo" (n. 2-12, p. 360). Enfatizam que a "nossa irremediável origem portugueza e o vínculo prejudicial da língua", "a muito nos obrigam" a manter uma "apparente camaradagem", que, na realidade, "revela mentiras e falsidades sem conta" (n. 2-12, p. 361). Segundo a edição, o passado em comum entre os países impele o Brasil a permanecer nesse "jugo funesto", no qual antes tivesse o país americano "ficado virgem de uma 'tal descoberta', a ter de haver-se com a moralidade da escravidão e do latrocínio e da eloquencia do incêndio e da balança, em que se pesavam aquellas gananciosas consciências!!" (n. 2-12, p. 361).

"Brazilea" "***** analisa, em suas edições, as ações de personagens históricos e critica a perspectiva que enaltece a presença portuguesa nos territórios brasileiros. No texto "A emancipação do Brazil", publicado na edição número 6, argumenta-se que D. Pedro I não deve ser considerado o patriarca da Independência, pois, desse modo, ignoram-se os fatores ligados à questão social na autonomia da nação. O texto disserta que é necessário abolir o "culto do heroísmo portuguez, do idealismo portuguez, do snobismo e do chauvismo também portuguezes" (n. 2-12, p. 241), que foi incutido aos brasileiros ao longo do tempo como modo de pensar, valorizando a memória e os costumes portugueses.

Na seção "bibliografia" da mesma edição, Jackson Figueiredo afirma que ele mesmo tinha uma noção enviesada da história brasileira, pois ignorava a importância da Revolução Pernambucana para a soberania da nação e também para a escrita da verdadeira história nacional do Brasil. Para ele, enquanto os outros países da América do Sul reagiram de forma abrupta contra as suas metrópoles, o Brasil manteve uma relação amistosa com os que se "julgam senhores dessa terra" e "continuamos a arrastar commercial e moralmente,

\footnotetext{
${ }^{* * * * *}$ Texto sem identificação de autoria. O sumário do número 6 da revista associa o texto à redação de "Brazilea".
} 
o mesmo jugo colonizados" (n. 2-12, p. 274). Nesse sentido, Jackson Figueiredo defende que os revolucionários pernambucanos foram proféticos ao perceber, desde antes da Independência, que a necessidade de "levantar o nível social dos homens de côr" não viria dos pensadores "endeusadores do luso-brasileirismo" (p. 274). Portanto, para ele, a única aliança possível seria àquela entre as nações latino-americanas, irmãs de sangue, criadas nas mesmas lutas e sofredoras dos mesmos males.

b) Intelectualidade

Os textos que versam sobre o campo das ideias e do pensamento intelectual revelam o desejo de emancipação brasileiro. Segundo a "Brazilea", havia um "exagerado culto do intelectualismo português", impondo ao povo brasileiro uma "pesada ditadura intelectual lusitana". Para rompê-la, seria necessário "cortar pela raiz nossa tradição, relegando os pontos de contato com a metrópole" (n. 2-12, p. 238).

O mensário valorizava o pan-americanismo, a nação e o patriotismo contra o estrangeirismo (n. 2-12, p. 411). Assim, de acordo com os colaboradores da revista, para alcançar a emancipação intelectual era necessário à imprensa se "tornar genuinamente brasileira" (n.2-12, p. 409), "fazendo propaganda do Brasil, dentro do Brasil" (n. 2-12, p. 467). Devia-se, portanto, evitar "uma tolerância exagerada" e "hospitalidade excessiva", ao "persistir na defesa indireta da escravidão intelectual" do Brasil em relação a Portugal (n. 212, p. 608).

A revista também se preocupou em destacar nomes da intelectualidade brasileira como Manoel Bomfim, Machado de Assis, Affonso Celso, Quintino Bocayuva, Sylvio Romero, Raymundo Corrêa, Adolpho Caminha, Castro Alves, Augusto Gil - para defender que no Brasil havia uma nova geração de jornalistas, cientistas, escritores, juristas e religiosos que "dão uma lição aos antigos colonizadores" e que são "infinitamente superiores às gerações passadas" (n. 2-12, p. 509). Acrescenta ainda que a intelectualidade brasileira se distinguia de parte da imprensa do Rio de Janeiro, que tinha como "escopo principal glorificar Portugal" (n.2-12, p. 224).

Ainda segundo a revista, o pensamento erudito português e a imprensa portuguesa refletiam preconceitos de raça e de cor. Nesse sentido, os colaboradores da "Brazilea" sugerem que esse preconceito se deve ao receio dos europeus de "se depararem com qualidades mais nobres e relevantes virtudes mais apreciáveis que as dos portugueses" (n. $2-12$, p. 178). Ainda ressaltam que se o brasileiro miscigenado é uma "raça inferior, se deve 
não pelos negros e índios, mas por todas as oficialidades, repartições publicas, artes [...] sendo dominadas por descendentes próximos dos nossos descobridores". Para a "Brazilea", "a raça branca portuguesa seria a causadora do nosso mal-estar e patente aniquilamento" (n. 2-12, p. 178).

Em diversos textos que desvelam a questão racial, os autores destacam trechos de obras literárias, a exemplo da citação oriunda do livro "América Latina: males de origem", de Manoel Bomfim ${ }^{\dagger+t+1}$ "É impossível ver um negro sem sentir-se atraído por ele. Tem fisionomias alegres, francas e honestas, o corpo sobejamente musculoso. Nunca pude olhar esses enfezados portugueses, com seu aspecto sanguinário, sem desejar por assim dizer, que o Brasil siga o exemplo do Haiti" (n. 2-12, p. 281 e 282).

Numa tentativa de se contrapor às narrativas que exaltavam os portugueses e glorificavam o vínculo intelectual e fraternal entre os países, a "Brazilea" afirmava que a "história do Brasil feita por portugueses e continuada por seus descendentes, idealistas e servis, é um amontoado de carapetões, tendentes a justificar os males sem conta que ficaram de uma tão acanhada civilização" (n.2-12, p. 361). Assim, os textos da revista argumentam que, devido aos aspectos econômicos, sociais, políticos e jurisdicionais, os portugueses sejam considerados estrangeiros e devam ser tratados como tais (n. 2-12, p. 374).

c) Comércio

Os textos da "Brazilea" que dissertam sobre a presença de portugueses no comércio brasileiro criticam a usurpação dos imigrantes lusos, principalmente na cidade do Rio de Janeiro. A revista afirma que, mediante apoio e contratos de conterrâneos, os comerciantes e trabalhadores portugueses chegavam ao Brasil e impunham seu modo de negócio especulativo, com a precificação exorbitante de produtos.

Bomílcar discorre que os portugueses apresentavam um "odioso privilégio" no comércio e o exerciam com "soberano despreso pelos interesses do povo e do paiz" (n. 2-12, p. 371). Segundo o editor, a administração comercial portuguesa não ajudava o país, uma vez que preferia a contratação de patrícios a brasileiros miscigenados e de cor, e também por enviar grande parte das remessas conquistadas para Portugal a fim de aumentar o enriquecimento

†tt†† BOMFIM, Manoel. A América Latina: males de origem. Rio de Janeiro: Centro Edelstein de pesquisas sociais, Biblioteca Virtual de Ciências Humanas, 1905. 
daquele país europeu, como no excerto: "As correntes de emigração portugueza essencialmente comerciais, são parasitariamente perigosas e nenhuma compensação nos offerecem com os seus processos rotineiros, em que a seva ganacia a tudo açambarca", pois " $95 \%$ das nossas rendas, que daqui se escoam annualmente em saques para a europa são 'serviços' mais relevantes, o 'beneficio' mais evidente que nos presta o commercialismo portuguez que tanto nos tem infelicitado" (n. 2, p. 240).

Ele alega que esses imigrantes atuavam como "senhores e assumem o papel commodo de intermediarios das classes produtoras, ditando leis contra o agricultor, contra o industrial, contra o operariado" (n. 2-12, p. 371). Em relação à atuação portuguesa no comércio, o trabalhador brasileiro "vê-se enxotado dentro do seu próprio país", se sentindo inútil, incapaz e subjugado. Dessa forma, o brasileiro, para Bomílcar, "só pode aproximar-se do balcão como consumidor... e consumidor altamente ludibriado" (n. 2-12, p. 371).

Os colaboradores da revista criticam os imigrantes portugueses por preferirem trabalhar no comércio das grandes cidades, diferentemente dos imigrantes italianos e alemães, que se dedicavam à agricultura no interior, ajudando o crescimento econômico do país, como no seguinte trecho: "É indesejável o aldeão português que não procura nosso campo, mas nosso litoral com o apoio de compatriotas, enchendo as cidades com suas tascas imundas, quitandas, casas lotéricas que envergonham nossa entrosada civilização" (n. 2-12, p. 239). Ainda segundo eles, para sanar esses problemas seria preciso implantar a nacionalização do comércio brasileiro como "único remédio a tantos males" (n. 2-12, p. 374), rompendo a tradição que privilegia os descendentes dos navegadores como comerciantes no Brasil.

Percebe-se, portanto, que os textos em análise demonstram o esforço da equipe editorial da revista em tornar proeminentes as diferenças entre os brasileiros e os portugueses. Num processo de afastamento entre Brasil e Portugal, defendiam a necessidade de corte "do cordão umbelical que prende [o Brasil] à antiga metrópole" (n. 1, p. 26) e rechaçavam a relação de dependência no processo de "retrograda tutela que põe insuperáveis barreiras a nossa civilisação" (n.2-12, p. 241).

\section{Considerações finais}

Os textos publicados em "Brazilea", no ano 1917, simbolizam o desejo de emancipação e rompimento com Portugal e a tentativa de banir da narrativa nacional os históricos vínculos entre os dois países. Para reforçar a perspectiva nativista, os editores e colaboradores da revista criticam as ações da Corte, as intenções dos descobridores e o 
caráter da monarquia portuguesa. Classificam as heranças históricas como "péssimo" (n.212, p. 152) passado e consideram como legado "vicioso" dos portugueses a "jactância, trapaça, chicana, prosápia fofa, tolice, preguiça, falta de sentimento de dever" (n. 2-12, p. 331), a quem atribuem "o preconceito de raça, o racismo, a escravidão, moralidade do latrocínio, barbarismo e o egoísmo" (n. 2-12, p. 281, 360, 370).

A crítica ao elo intelectual entre os países - representado pelos Gabinetes Reais de Leitura, Instituto Histórico Geográfico, Confederação Luso-Brasileira e participação de portugueses na imprensa de São Paulo e do Rio de Janeiro - denota intolerância dos editores para com os pensadores portugueses, em nome do ideal nacionalista. Para a equipe editorial, a "tolerância" (n. 2-12, p. 238) e o "culto exagerado do intelectualismo português" (n.2, p. 608) no Brasil fortalecem a "retrograda tutela que põe insuperáveis barreiras a nossa civilisação" (n.2-12, p. 241) e o "jugo funesto" (n.2-12, p. 361), que impedem a emancipação e o corte do vínculo entre pensadores dos dois lados do Atlântico.

A revista rechaça a participação de imigrantes lusos no comércio brasileiro. Os editores acusam os imigrantes de parasitismo no comércio - sustentado pela precificação exorbitante e ludibriação do consumidor (n. 2-12, p. 360 e 371) - e de não oferecer compensação, pois suas rendas e remessas são destinadas aos familiares na Europa ( $n$. $2-12$, p. 240). A concorrência entre brasileiros e portugueses no mercado de trabalho como pesquisaram Ribeiro (2017) e Mendes (2010; 2011) - marcam o embate e o antagonismo, aspectos desvelados nas narrativas de "Brazilea", os quais alimentam a separação identitária entre os dois países.

Nota-se ainda que a estratégia narrativa da revista "Brazilea" visava à ressignificação da memória histórica - a qual inclui rastros, indícios, vestígios, símbolos, arquivos e documentos (RICOEUR, 1994) -, ao considerar, na construção da identidade nacional, a presença de Portugal como um "piano velho que nos mandassem de além-mar, com as téclas e cordas bem estragadas..." (n.1, p. 28). É nesse sentido que as memórias coletivas — simbolizadas neste trabalho pelas perspectivas de "Brazilea" - representam, como ressaltam Halbwachs (1990), Pollak (1992) e Casalegno (2006), as experiências comuns de um grupo social - no caso em análise, os nativistas - a partir das demandas do momento em que são articuladas e compartilhadas por meio do processo narrativo.

Desse modo, o exposto em "Brazilea" representa o antagonismo na construção da narrativa nacional, que alimentou o estranhamento e (in) comunicação entre as nações, descritos por Fino (2019). Essas narrativas, com cariz nativista, simbolizam a legitimação 
do conceito de nação, presente no pensamento do final do século XIX e ínício do século XX no Brasil e na Europa (KHALED, 2010).

Por fim, entende-se que o antagonismo entre Brasil e Portugal pode ser apreendido como um vestígio que infunde um pensamento xenófobo contra os portugueses, uma espécie de lusofobia. Sugere-se, em acréscimo, futuras pesquisas sobre o fenômeno, tanto pelo estranhamento - uma vez que os brasileiros não se consideram xenófobos com relação a Portugal — como também pela investigação das origens xenófobas no Brasil.

\section{Referências}

ADAMEC, Martin. A formação da identidade nacional brasileira: um projeto ressentido. Tese de Doutorado. Instituto de Ciência Política da Universidade de Brasília, 2014.

ALVES, Jorge Luís dos Santos. Malheiro Dias e o luso-brasileirismo: um estudo de caso das relações culturais Brasil-Portugal. Tese de Doutorado. Departamento de História da Universidade do Estado do Rio de Janeiro, 2009.

BRASILIENSE, Américo. Manifesto Republicano. São Paulo: EADUSP, 1870. Disponível em:<https://edisciplinas.usp.br/pluginfile.php/4360902/mod_resource/content $/ 2 /$ manifesto \%20republicano\%201870.pdf>. Acesso em junho de 2020.

BRAZILEA, Revista Mensal de Propaganda Nacionalista. Edições 1-12. Rio de Janeiro, 1917.

BOMFIM, Manoel. A América Latina: males de origem. Rio de Janeiro: Centro Edelstein de pesquisas sociais, Biblioteca Virtual de Ciências Humanas, 1905.

CALHOUN, Craig. Nationalism. Minneapolis: University of Minnesota Press, 1997.

CASALEGNO, Federico. Memória Cotidiana: Comunidades e comunicação na era das redes. Porto Alegre: Sulina, 2006.

CATROGA, Fernando. Memória, história e historiografia. Rio de Janeiro: Editora FGV, 2016.

DE LUCA, Tania Regina (org). Catálogo da Hemeroteca do Centro de Documentação e Apoio à Pesquisa (Cedap). São Paulo: FCL-UNESP- Assis, 2011. Disponível em: $<$ https://www.assis.unesp.br/Home/pesquisa/cedap/catalogo_hemeroteca.pdf>. Acesso em junho de 2020.

FINO, Carlos Alberto. Raízes do estranhamento: a (in) comunicação Portugal-Brasil. Tese de Doutorado. Departamentos de Comunicação das Universidade do Minho e Universidade de Brasília, Brasília (Brasil) e Braga (Portugal), 2019. 
GOMES, Amanda Muzzi. Jacobinos: abordagem conceitual e performática. Revista Cantareira, Rio de Janeiro, v. 12 (UFF online), p. 1-19, 2008. Disponível em: $<$ http://www.periodicos.uff.br/cantareira/article/view/27848/16255>. Acesso em 20 de maio de 2020.

HALBWACHS, Maurice. A memória coletiva. São Paulo: Editora Vértice, 1990.

INSTITUTO BRASILEIRO DE GEOGRAFIA E ESTATÍSTICA (IBGE). Recenseamento do Brazil de 1 de setembro de 1920: vol. II - $1^{\text {a }}$ parte. População do Rio de Janeiro (Districto Federal). Rio de Janeiro: Typographia da Estatística, 1923. Disponível em: <https://biblioteca.ibge.gov.br/visualizacao/livros/liv6383.pdf>. Acesso em junho de 2020.

JANCSÓ, István; PIMENTA, João Paulo. Peças de um mosaico (ou apontamentos para o estudo da emergência da identidade nacional brasileira). In: MOTA, Carlos Guilherme (org). Viagem Incompleta: a experiência brasileira. (1500-2000). São Paulo: Senac, 1999, p. 127-176.

JESUS, Carlos Gustavo. Revista Gil Blás e o nacionalismo de combate (1919-1923). São Paulo: Editora Acadêmica, 2012.

KHALED, Salah. Horizontes Identitários: a construção da Narrativa Nacional Brasileira pela Historiografia do Século XIX. Porto Alegre: EDIPUCRS, 2010.

LIMA, André. Rusga: participação política, debate público e mobilizações armadas na periferia do Império (província de Mato Grosso, 1821-834). Tese de Doutorado em História Social. Faculdade de Filosofia, Letras e Ciências Humanas, Universidade de São Paulo, 2016.

MENDES, José Sachetta. Laços de Sangue: Privilégios e Intolerância à Imigração Portuguesa no Brasil. Porto: Cepese, 2010.

"Somos da América e queremos ser americanos": relações BrasilPortugal e antilusitanismo na fundação da República. Revista do Instituto Histórico e Geográfico Brasileiro (IHGB), v. 172, n. 452, 2011, p. 355-371.

OLIVEIRA, Carla Mary. Imprensa e imigração na República Velha: a revista Lusitânia e a colônia luso-carioca (1929-1934). Portuguese Studies Review, Lisboa, v. 12, n. 1, 2004, p. 143-161.

OLIVEIRA, Lucia Lippi. A questão nacional na primeira República. São Paulo: Brasiliense, 1990.

POLLAK, Michael. Memória e identidade social. Revista de Estudos Históricos. v. 10, n. 5, 1992, p. 200-215.

QUEIROZ, Suely Robles. Os Radicais da República. São Paulo: Brasiliense, 1986.

RIBEIRO, Gladys Sabina. A liberdade em construção: identidade nacional e conflitos antilusitanos no Primeiro Reinado. Rio de Janeiro: Relumé Dumará, 2002. 


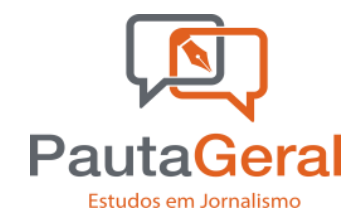

Gladys Sabina. O Rio de Janeiro dos fados, minhotos e alfacinhas: o antilusitanismo na Primeira República. Rio de Janeiro: Eduff, 2017.

RICOEUR, Paul. Tempo e narrativa (tomo 1). Trad. Constança Marcondes Cesar. Campinas: Papirus, 1994.

SANTOS, Wilza Betania. Identidades, Convivências e Histórias: os Gabinetes Portugueses de Leitura de Pernambuco e da Bahia (1850-1931). Tese de Doutoramento em História. Faculdade de Letras da Universidade do Porto, 2018. 